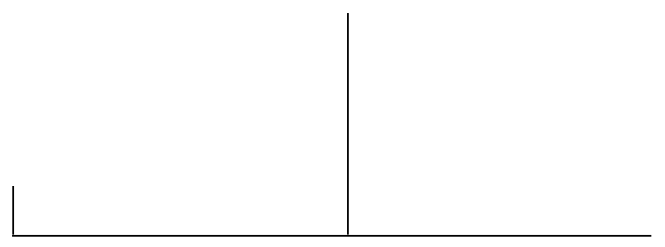

Rev. Latinoam. Psicopat. Fund., São Paulo, v. 13, n. 2, p. 296-306, junho 2010

\title{
Jean-Pierre Falret e a definição do método clínico em psiquiatria
}

\author{
Fernando A. da Cunha Ramos
}

Jean-Pierre Falret pode ser considerado a terceira grande figura da medicina mental francesa da primeira metade do século XIX, tendo sido aquele que, após Pinel e Esquirol, foi responsável por dar o acabamento final à obra de fundação da psiquiatria clínica e da patologia mental. A vida de Falret coincide no tempo com o período de domínio cultural e político da França no Ocidente, no qual também a medicina mental francesa se desenvolveu e alcançou seu ápice. Após a morte de Falret, a psiquiatria francesa entra em um lento processo de decadência, sendo sua liderança gradualmente substituída pela da escola psiquiátrica germânica, a qual, ao final do século XIX e início do século $X X$, dará desenvolvimento a muitas das idéias desse autor. $O$ capítulo introdutório de sua principal obra, Des maladies mentales et des asiles d'aliénés, publicada ao final de sua vida, é considerado, ele próprio, uma obra-prima. Nele, Falret faz a síntese de sua carreira intelectual e clínica, realizando um trabalho de crítica e revisão de inúmeros conceitos da medicina mental da época. Entre as grandes contribuições de Falret, está a definição precisa do método clínico em psiquiatria, com seus três principais aspectos: o enquadre dialético, a perspectiva evolutiva e a supremacia do sujeito psíquico.

Palavras-chave: Método clínico, Falret, dialético, evolutivo, psicopatologia 
Quando olhamos, em retrospecto, para o que foi a medicina mental francesa em meados do século XIX, e para o papel que esta desempenhou no cenário cultural da época, é impossível não nos depararmos com a figura grandiosa de Jean-Pierre Falret. Indubitavelmente, Falret foi um desses "gigantes" descritos por Isaac Newton, em cujos ombros, nós, meros anões intelectuais, nos sentamos para poder enxergar mais longe. Praticamente todos os alicerces da psiquiatria clássica, que somente encontrarão sua plenitude no período de domínio da escola psiquiátrica germânica, que se seguirá à morte de Falret, podem ser encontrados, já bastante elaborados, na obra monumental desse autor. Lá está o conceito da clínica como exercício fundamentalmente dialético; lá está a exigência do equilíbrio entre observação, teoria e prática; lá está a necessidade de se valorizar as entrelinhas, o contexto, o não dito; lá está a valorização da história, do processo, da temporalidade evolutiva, como o fio de Ariadne capaz de orientar o diagnóstico e a direção do tratamento; enfim, lá está a percepção profunda e aguda de que a psicopatologia é, antes de tudo, o trabalho singular de um sujeito desafiado por uma alteridade que o atravessa e o invade.

Nascido durante a Revolução Francesa, em Marcillac-duLot, em junho de 1794, no auge do "Terror" revolucionário, Falret $^{1}$ veio a falecer, em outubro de $1870,{ }^{2}$ aos 76 anos de idade, em sua cidade natal, no momento em que Paris se encontrava cercada pelo exército prussiano, já prestes a capitular (cf. Loiseau, 1872). Será seu filho, Jules Falret, que, presidindo a primeira sessão da Société Médico-Psychologique após o término do conflito, dará a seus colegas a triste notícia do falecimento do pai (cf. Semelaigne, 1930, p. 179).

1. Mais precisamente no dia 7 de Pradial (Prairial), conforme o calendário revolucionário da época.

2. Em 28 de outubro de 1870. Na véspera, 27 de outubro, o Marechal Bazaine, com um exército de 173.000 homens, já havia apresentado, em Metz, sua rendição. 


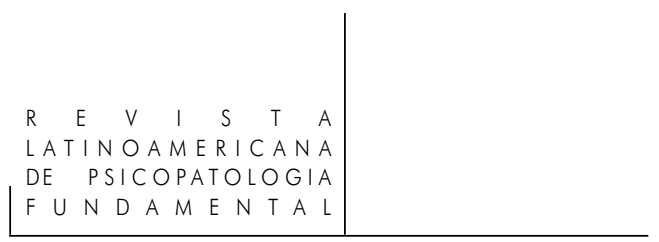

Essa moldura histórica, que situa a biografia de Falret entre a Revolução Francesa, que alçou a França à primeira posição política e cultural no Ocidente, e a derrota na Guerra Franco-Prussiana, de cuja humilhação a nação francesa jamais conseguirá se recuperar de modo completo, encontra também o seu equivalente no percurso realizado pela medicina mental no mesmo período.

De um lado, o ano de nascimento de Falret, 1794, é também o ano em que Philippe Pinel apresenta, diante da Sociedade de História Natural de Paris, sua primeira "memória" sobre a alienação mental (cf. Pinel, 1794), marcando o que será o primeiro passo na criação da médecine mentale francesa, assim como o primeiro degrau na ascensão da França à liderança nesse campo (cf. Weiner, 1992). ${ }^{3}$ De outro, a derrota vexaminosa da França na Guerra Franco-Prussiana, no ano de falecimento de Falret, em 1870, representou o fim do domínio francês e o início do alemão na nova disciplina médico-psicológica que, agora, em vez de ser chamada, dialogicamente, de medicina mental, na tradição francesa, e de medicina psicológica, na escola britânica, passará a ser conhecida, monoliticamente, como psiquiatria.

Dessa forma, a vida de Falret coincide no tempo com o ciclo áureo da medicina mental francesa. O fastígio dessa última, entre os anos 1830 e 1850, incluindo a promulgação da lei de 30 de junho de 1838, o lançamento dos Annales Médico-Psychologiques, em 1843, e a fundação da Société MédicoPsychologique, em 1852, coincidem com o ápice da carreira de Falret. Foi este o período em que Falret produziu o melhor de sua obra, começando pelo livreto sobre o projeto de lei a respeito dos alienados (cf. Falret, 1837), publicado em 1837, e se encerrando com os artigos magníficos sobre o ensino clínico das doenças mentais (cf. Falret, 1864b), de 1850, sobre a não existência da monomania (cf. Falret, 1854), de 1854, e sobre o conceito de insanidade circular (cf. Falret, 1854), também de 1854. Portanto, Falret foi, durante toda a sua vida, não apenas espectador privilegiado, mas, sobretudo, protagonista decisivo do processo de desenvolvimento da psiquiatria durante sua fase mais brilhante de fundamentação.

Após os anos 1870, a medicina mental francesa enfrentará um processo lento, mas inexorável, de decadência. $\mathrm{O}$ envolvimento crescente dos alienistas com o partidarismo político, o abandono e degradação progressiva da rede asilar na França - acompanhada por uma crítica incansável e violenta da imprensa, contestando a legitimidade da medicina mental como campo científico e institucional (cf. Goldstein, 2001) -, e o estabelecimento da teoria da degenerescência tão combatida por Falret - como panaceia teórica capaz de servir de esteio a uma

3. No dia 11 de dezembro de 1794.

Rev. Latinoam. Psicopat. Fund., São Paulo, v. 13, n. 2, p. 296-306, junho 2010 
medicina mental que naufragava a olhos vistos (cf. Dowbiggin, 1991), impediram, em conjunto, que a medicina mental francesa sustentasse sua liderança frente ao avassalador crescimento e fortalecimento da escola psiquiátrica germânica com a unificação da Alemanha após a vitória esmagadora na Guerra Franco-Prussiana. A nação francesa e sua médecine mentale serão tomadas por um pessimismo incurável. Curiosamente, será a obra de um discípulo de Falret, Bénédict-Augustin Morel - que havia sido o primeiro a traduzir as obras psiquiátricas alemãs para o idioma francês -, que servirá de guia para a idade de bronze que se instalará na medicina mental francesa após a morte de Falret.

Dessa forma, pode-se dizer que, da trindade fundadora da medicina mental francesa, e, portanto, da psiquiatria moderna, Falret foi aquele que, sendo o terceiro elo de sua linhagem, deu o acabamento final ao trabalho iniciado por seus antecessores e mestres, Pinel e Esquirol. Se, nessa trindade autoral, Pinel foi o Pai, e Esquirol o Filho, Falret, por sua vez, foi o Espírito Santo do alienismo francês. ${ }^{4}$ Contudo, é necessário destacar que a relação entre esse trio de autores não se define por uma homogeneidade consubstancial. De modo algum. Trata-se, ao contrário, de uma série trinária marcada, dialeticamente, por fortes continuidades, mas também por importantes rupturas.

Tal como Pinel e Esquirol, Falret foi um homem do Midi, da Province, em busca das luzes parisienses. Assim como seus mestres, teve sua formação inicial de médico no seio "vitalista" de Montpellier. Da mesma forma que seus antecessores, foi, antes de tudo, um homem da Salpêtrière, e, por conseguinte, alguém que desenvolveu sua obra teórica e prática no denso contexto da psicopatologia feminina. ${ }^{5} \mathrm{E}$, por fim, tal como seus predecessores, dedicou a sua vida inteira ao ensino clínico da medicina mental.

Esses quatro pontos de continuidade entre Falret e seus mestres, Pinel e Esquirol, são importantes na compreensão da obra desses três autores, pois nem a origem provinciana comum, nem o compartilhamento de uma mesma educação médica, nem a imersão no universo psicológico feminino, nem a preocupação com

4. A analogia aqui não é gratuita. Falret pertencia a uma família religiosa, e, durante várias gerações, seus parentes estiveram entre os monges beneditinos da Abadia de Marcillac, inclusive seu irmão caçula. Em 1843, ele fundará, juntamente com o abade Christophe, capelão de seu serviço na Salpêtrière e futuro bispo de Soissons, uma instituição de patronagem para as alienadas convalescentes (Cf. Annales Médico-Psychologiques, 2004). Além disso, do ponto de vista científico, Falret era considerado, no auge de sua carreira, um médico-filósofo espiritualista.

5. Há toda uma história ainda a ser escrita sobre o lugar da mulher na construção do campo da psicopatologia, lugar este que não se restringe ao papel da mulher histérica no período dominado por Charcot na Salpêtrière, como se costuma pensar. 
o ensino clínico, foram indiferentes ao percurso solidário traçado em conjunto por essas três grandes figuras da medicina mental francesa. O descentramento facultado pelo berço provinciano permitiu-lhes que conservassem sempre uma distância tática em relação aos modismos intelectuais reinantes em Paris, dando-lhes uma notável autonomia criativa. A formação dentro do espírito vitalista de Montpellier marcou-os, indelevelmente, com uma forte rejeição à ideia mecanicista de se reduzir o psíquico ao físico, e com uma enorme afeição ao preceito de se tratar a dimensão subjetiva em seus próprios termos (cf. Williams, 1994). A imersão no mundo da psicologia feminina - em plena era romântica, na qual a mulher se destacava como protagonista - abriu-lhes um rico manancial de produção narrativa e expressão afetiva a ser explorado. Finalmente, a dedicação intensa ao ensino clínico obrigou-os a um constante refinamento, sistematização e renovação de ideias frente ao desafio ininterrupto dos jovens alunos que se sucediam ano após ano, sempre provocadores e atraídos pelas novidades da moda intelectual.

Mas as diferenças também não foram poucas entre essas figuras fundadoras. Falret retoma, vigorosamente, o trabalho teórico iniciado, de forma cautelosa, por Pinel, mas abandonado e rechaçado por Esquirol ${ }^{6}$ após uma tentativa frustrada em sua tese inaugural (cf. Esquirol, 1805). Na clínica - onde Pinel restringiu-se a traçar em grandes pinceladas os aspectos principais, e onde Esquirol esforçou-se em diferenciar e esmiuçar os detalhes e sutilezas, fundando a semiologia psiquiátrica e a psicopatologia - Falret, por sua vez, se impôs a tarefa de realizar a integração do edifício psicopatológico, recusando qualquer forma de fragmentação do psíquico.

As "psicologias" de referência empregadas pelos três autores também foram bastante distintas. Pinel se valeu da idéologie de Destutt de Tracy e Pierre Cabanis, que, por sua vez, seguiam no rastro do empirismo de Locke e do sensualismo de Condillac (cf. Staum, 1980). Nessa primeira psicologia da medicina mental, a principal faculdade psíquica, seja nas condições psicológicas normais, seja na psicopatologia, era a imaginação. Nela, o sujeito se via atingido, passivamente, por impressões que, vindas inteiramente de fora, lhe bombardeavam e moldavam a

6. Após um breve entusiasmo com a especulação teórica, no início de sua carreira, quando, na sua tese inaugural de 1805, desenvolveu um elaborado argumento a respeito do papel das paixões na etiologia, expressão clínica e tratamento da alienação mental, Esquirol foi se tornando cada vez mais reservado em relação ao trabalho teórico até, por fỉm, assumir uma posição totalmente cética. A obra síntese do final de sua vida, Des maladies mentales, que reuniu todos os artigos anteriormente publicados de forma dispersa, deixou, não obstante, a tese inaugural de fora, ao passo que o capítulo introdutório ressaltava a desconfiança de Esquirol em relação aos sistemas teóricos. 
mente. Esquirol, a seu turno, abandona esse esquema excessivamente passivo e limitado em prol da psicologia ativista de Laromiguière, na qual é a faculdade de atenção que se destaca como lócus principal da psicopatologia. Falret, por fim, tomará, como suporte do seu pensamento, a psicologia do senso comum de Thomas Reid, de origem escocesa, e, particularmente, a psicologia espiritualista, ou eclética, de Victor Cousin (cf. Nicolas, 2001). Esta última, de enorme influência cultural na França de meados do século XIX (cf. Goldstein, 2005), dava ao "moi", ao sujeito autoconsciente, o protagonismo principal na elaboração psíquica.

Contudo, será na explicitação, pela primeira vez, do método clínico em psiquiatria que Falret se distinguirá marcadamente dos seus mestres e antecessores. O texto de Falret que o leitor terá o prazer de ler, após essas breves linhas de apresentação, constitui um extrato do capítulo introdutório da obra síntese desse autor, publicada ao final da sua vida, da mesma forma e com o mesmo título que aquela de seu mestre Esquirol. Mas, se por um lado, o modo simbólico de encerrar a sua carreira representa, sem dúvida, uma clara homenagem ao mestre, por outro, o capítulo introdutório constitui uma evidente demonstração da distância que os separa. Nessa Introduction, Falret define detalhadamente, por meio de uma elaborada discussão teórica, aquilo que para ele representa o verdadeiro método clínico.

Embora, em sua maioria, os historiadores estejam de acordo que o essencial da obra de Falret esteja contido entre os anos 1830 e 1850, eles também concordam, não obstante, que o texto que ocupa o lugar de obra-prima na vasta produção bibliográfica de Falret é esse rebento tardio, surgido em 1863, quando o autor já se aproximava dos setenta anos de idade. Porém, não são apenas os historiadores da atualidade que pensam assim, os contemporâneos de Falret também tinham essa opinião, tal como nos revela o testemunho de um discípulo de Falret, J. M. Gardia, publicado logo após o falecimento do mestre:

Aqueles instruídos na patologia mental não terão dificuldade em reconhecer que ele era o primeiro entre seus pares. Não é temerário afirmar que o volume, no qual se encontram reunidos os seus principais trabalhos sobre as doenças mentais e os asilos de alienados, será lido pela posteridade. Não hesitamos em repetir aquilo que já dissemos alhures, ou seja, que o capítulo introdutório dessa coletânea tão preciosa constitui uma obra prima de ciência sólida, sabedoria prática e sinceridade. (cf. Gardia, 1872, p. 28)

O ponto alto desse texto magnífico é precisamente a longa exposição que Falret faz daquilo que ele denomina de la méthode clinique. Podemos identificar no método clínico de Falret três aspectos principais, a saber: um enquadre dialético, uma perspectiva evolutiva, e uma ênfase no protagonismo do sujeito psíquico. 
No enquadre dialético, Falret destaca a irredutibilidade entre o físico e o psíquico, e a necessidade de integrá-los na compreensão e manejo da psicopatologia. No entanto, não se detém apenas nesse aspecto, salientando também a importância de se articular o dito com o não dito, e aquilo que se manifesta com aquilo que está em falta. Falret desenvolve uma série de ideias originais, nessa introdução, que somente serão plenamente destiladas por Karl Jaspers, cerca de meio século depois, com os conceitos de verstehen e erklaren. De forma muito interessante, Falret ilustra como que o próprio desenvolvimento do método clínico em seu pensamento se deu por meio de um processo dialético ao longo da sua carreira, onde, após oscilar entre uma posição organicista e uma psiquista, acabou por chegar à síntese clínica.

Na perspectiva evolutiva, ou longitudinal, Falret destaca a psicopatologia como produção histórica, como processo em permanente construção, cuja elucidação só pode se dar quando se considera o desenvolvimento no tempo como elemento analítico. Assim, as entidades clínicas devem ser caracterizadas por sua existência diacrônica e não, como pretendiam Pinel e Esquirol, por suas manifestações transversais e sincrônicas. Tais ideias, no entanto, terão de esperar o trabalho de Emil Kraepelin para encontrarem, na virada do século XIX para o XX, o seu desenvolvimento e sistematização definitivos (cf. Kraepelin, 1990).

Por fim, a ênfase na supremacia do sujeito psíquico leva às últimas consequências a dupla descoberta feita por Pinel, e salientada por Hegel - o inventor do método dialético -, de que sempre "há um resto de razão nos alienados e maníacos, [e] (...) de que nesse fato é que está contido o princípio de sua cura" (cf. Swain, 1994, p. 10). Assim, desenvolvendo a ideia fundadora da medicina mental de que o louco é sujeito de sua loucura (cf. Swain, 1997), Falret chega a afirmar que, na alienação mental, a "modificação orgânica primitiva" tem apenas o papel restrito de gerar a "aptidão a delirar" (cf. Falret, 1864a, p. XII-XIII), sendo tudo o mais pura produção narrativa de um sujeito singular e historicamente dado. Também aqui será preciso aguardar o trabalho de Eugen Bleuler que, no início do século $\mathrm{XX}$, promovendo o conúbio da psicanálise debutante com a psiquiatria madura, lançará os conceitos de sintomas fundamentais e sintomas acessórios, sendo os últimos, não apenas aqueles que definem o essencial das manifestações psicopatológicas, mas também aqueles que são inteiramente produzidos pelo sujeito psicótico (cf. Bleuler, 1987).

Sem dúvida, o aprofundamento na obra de Jean-Pierre Falret deve constituir um exercício obrigatório para aqueles que se interessam tanto pela história da psiquiatria quanto pela psicopatologia comparada. A leitura do capítulo introdutório de sua opus magna é, portanto, um excelente ponto de partida. 


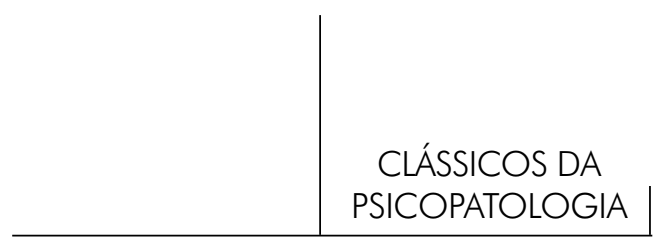

\section{Referências}

Annales Médico-Psychologiques. Dictionnaire biographique de psychiatrie par des membres de la Société Médico-Psychologique. Jean-Pierre Falret (1794-1870). Annales Médico-Psychologiques. 2004 (in press).

Bleuler, E. Dementia Praecox or the Group of Schizophrenias. Madison: International University Press, 1987.

Dowbiggin, I.R. Inheriting Madness: Professionalization and Psychiatric Knowledge in Nineteenth-Century France. Berkeley: University of California Press, 1991.

Esquirol, J.E.D. Des Passions, Considerées comme Cause, Symptômes et Moyens curatifs de l'Aliénation mentale. Paris: L'Imprimerie de Didot Jeune, 1805.

FALRET, J.P. Observations sur le projet de loi relatif aux aliénés. Paris: Imprimerie d'Adolphe Everat, 1837.

. De la non-existence de la monomanie. Archives Générales de Médecine, Paris, Ve série, Tome 4, p. 147-164, 1854a.

. Mémoire sur la folie circulaire. Bulletin de l'Académie Imperiale de Médecine, Paris, Tome XIX, p. 382-415, 1854b.

. Introduction. In: Des maladies mentales et des asiles d'aliénés: leçons cliniques et considérations generals. Paris: J.-B. Baillière et Fils, 1864a. p. I-LXIX.

. De l'enseignement clinique des maladies mentales (1850). In: Des maladies mentales et des asiles d'aliénés: leçons cliniques et considérations générales. Paris: J.-B. Baillière et Fils, 1864b. p. 147-164

GARDiA, J.M. Le docteur P. Falret. Gazette médicale de Paris: journal de médecine et des sciences accessories, Paris, série 3, n. 26, p. 25-28, 1871.

Goldstein, J. Console and Classify: The French Psychiatric Profession in the Nineteenth Century. Chicago: The University of Chicago Press, 2001.

$$
\text { . The Post-Revolutionary Self: Politics and Psyche in France, 1750-1850. }
$$

Harvard University Press, 2005.

Kraepelin, E. Psychiatry: A Textbook for Students and Physicians. Science History Publications, 1990.

LoISEAu, C. Éloge de Jean-Pierre Falret, lu dans la séance publique annuelle de la Société médico-psychologique du 18 décembre 1871. Paris: Imprimerie de E.

Donnaud, 1872.

Nicolas, S. Histoire de la psychologie. Paris: Dunod, 2001.

PINEL, P. Observations sur la manie pour servir l'Histoire naturelle de l'Homme. An II (1794). In: Postel, J. Genèse de la psychiatrie: les premiers écrits de Philippe Pinel. Institut Synthélabo, 1998. p. 231-246. 


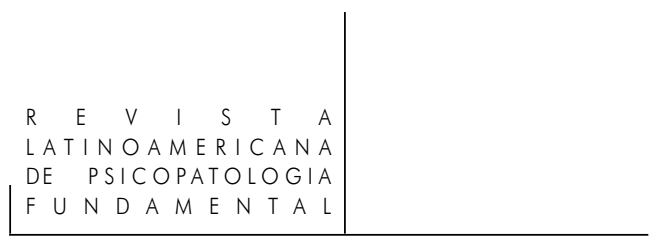

Rev. Latinoam. Psicopat. Fund., São Paulo, v. 13, n. 2, p. 296-306, junho

2010Semelaigne, R. Les pionniers de la psychiatrie française avant et après Pinel. Falret (Jean-Pierre). Paris: Librairie J.-B. Baillière et Fils, 1930. V. I, p. 172-179.

STAum, M.S. Cabanis: Enlightenment and Medical Philosophy in the French Revolution. Princeton: Princeton University Press, 1980.

Swain, G. De Kant à Hegel: deux époques de la folie. In: Dialogue avec l'insensé. Paris: Gallimard, 1994. p. 5-28.

. Le sujet de la folie: naissance de la psychiatrie. Paris: Calmann-Levy, 1997.

Weiner, D.B. Philippe Pinel's "Memoir on Madness" of December 11, 1794. American Journal of Psychiatry, v. 149, n. 6, p. 725-732, 1992.

Williams, E.A. The Physical and the Moral: Anthropology, Physiology, and Philosophical Medicine in France, 1750-1850. Cambridge: Cambridge University Press, 1994.

\section{Resumos}

(Jean-Pierre Falret and the definition of the clinical method in psychiatry)

Jean-Pierre Falret can be considered the third greatest figure in French mental medicine during the first half of the 19th century. It was he who, following Pinel and Esquirol, gave the final touches to works that constituted the foundations of clinical psychiatry and mental pathology. Falret lived during the time of French cultural and political domain in the West, a time that also corresponded to the high point of French mental medicine. After his death, French psychiatry entered a slow process of decline, as leadership in the field was gradually taken over by the German school of psychiatry, which, in the late 19th and early 20th centuries, further developed many of his ideas. His most important work is entitled Des maladies mentales et des asiles d'aliens, published late in life, and many consider its opening chapter a masterpiece. There the author presents a synthesis of his intellectual career and clinical practice, consisting, as it does, of critiques of numerous concepts in the mental medicine of the times. One of Falret's greatest contributions is his precise definition of the clinical method in psychiatry, with its three main aspects: the dialectic framework, the evolutionary perspective and the supremacy of the psychic subject.

Key words: Clinical method, Falret, dialectic, evolution, psychopathology

(Jean-Pierre Falret et la définition de la méthode clinique en psychiatrie)

Jean-Pierre Falret peut être considéré, a la suite de Pinel e Esquirol, une grande personnalité dans la médicine mentale française de la première moitie du XIXème siècle. 


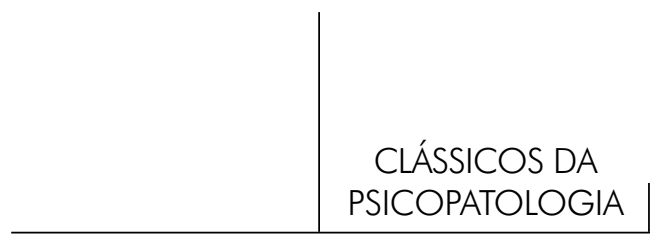

Il fut le responsable de l'achèvement final de l'œuvre de fondation de la psychiatrie clinique et de la pathologie mentale. La vie de Falret coüncide avec le période de domination culturelle et politique de la France en Occident pendant laquelle la médicine mentale française s'est développée et a atteint son apogée. Après la mort de Falret, la psychiatrie française s'enlise dans un lent déclin. Sa primauté fut peu à peu remplacée par l'école psychiatrique allemande, qui à la fin du XIXème et début du XXème siècle, développera un grand nombre d'idées de cet auteur. Le chapitre d'introduction de son cuvre majeure, Des maladies mentales et des asiles d'aliénés, publié vers la fin de sa vie, est considéré en soi un chef-d'euvre. Dans ce chapitre, Falret fait la synthèse de sa carrière intellectuel et clinique, réalisant un travaille de critique et révision de nombreux concepts de la médicine mentale de l'époque. On retrouve, parmi les grandes contributions de Falret, la définition précise de la méthode clinique en psychiatrie et ses trois principaux aspects: l'encadrement dialectique, la perspective évolutive et la suprématie du sujet psychique.

Mots clés: Méthode clinique, Falret, dialectique, évolutif, psychopathologie

(Jean-Pierre Falret y la definición del método clínico en psiquiatría)

Jean-Pierre Falret puede ser considerado la tercera gran figura de la medicina mental francesa de la primera mitad del siglo XIX, habiendo sido aquel que, después de Pinel y Esquirol, fue el responsable por dar el acabamiento final a la obra de fundación de la psiquiatría clínica y de la patología mental. La vida de Falret coincide en el tiempo con el período de dominio cultural y político de Francia en Occidente, en el cual también la medicina mental francesa se desarrolló y alcanzó su ápice. Después de la muerte de Falret, la psiquiatría francesa entra en un lento proceso de decadencia, siendo su liderazgo gradualmente substituido por el de la escuela psiquiátrica germánica, la cual, al final del siglo XIX e inicios del siglo XX, dará desarrollo a muchas de las ideias de este autor. El capítulo de introducción de su principal obra, Des maladies mentales et des asiles d'aliénés, publicada al final de su vida, es considerado una obra prima. En él Falret concretiza la síntesis de su carrera intelectual y clínica, realizando un trabajo de crítica y revisión de innúmeros conceptos de la medicina mental de la época. Entre las grandes contribuciones de Falret, está la definición precisa del método clínico en psiquiatría, con sus tres principales aspectos: o encuadre dialéctico, la perspectiva evolutiva y la supremacía del sujeto psíquico.

Palabras claves: Método clínico, Falret, dialéctico, evolutivo, psicopatología

Citação/Citation: Ramos, F.A.C. Jean-Pierre Falret e a definição do método clínico em psiquiatria. Revista Latinoamericana de Psicopatologia Fundamental, São Paulo, v. 13, n. 2, p. 296-306, jun. 2010.

Editor do artigo/Editor: Prof. Dr. Mário Eduardo Costa Pereira

Rev. Latinoam. Psicopat. Fund., São Paulo, v. 13, n. 2, p. 296-306, junho 2010 


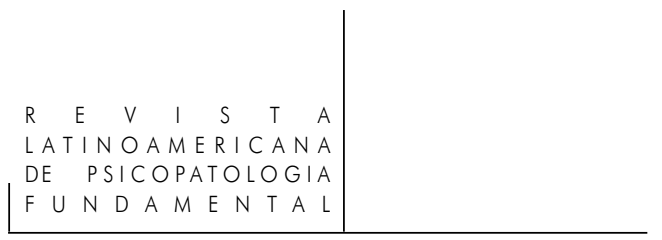

Recebido/Received: 22.4.2010 / 4.22.2010 Aceito/Accepted: 5.5.2010 / 5.5.20109

Copyright: () 2009 Associação Universitária de Pesquisa em Psicopatologia Fundamental/ University Association for Research in Fundamental Psychopathology. Este é um artigo de livre acesso, que permite uso irrestrito, distribuição e reprodução em qualquer meio, desde que o autor e a fonte sejam citados/This is an open-access article, which permits unrestricted use, distribution, and reproduction in any medium, provided the original author and source are credited.

Financiamento/Funding: $\mathrm{O}$ autor declara não ter sido financiado ou apoiado/The author has no support or funding to report.

Conflito de interesses/Conflict of interest: $\mathrm{O}$ autor declara que não há conflito de interesses/The author declares that has no conflict of interest.

\section{Fernando Augusto da Cunha Ramos}

Psiquiatra da infância e adolescência pela Associação Brasileira de Psiquiatria - ABP; especialista em gestão pela Escola Nacional de Saúde Pública da Fundação Oswaldo Cruz - ENSP/ Fiocruz (Rio de Janeiro, RJ, Brasil); presidente do Centro de Estudos e coordenador do Programa de Residência Médica em Psiquiatria do Instituto Philippe Pinel (Rio de Janeiro, RJ, Brasil); coordenador Geral da Escola de Saúde Mental do Rio de Janeiro - ESAM (Rio de Janeiro, RJ, Brasil); consultor do Ministério da Saúde nas áreas de educação na saúde e saúde mental infanto-juvenil.

Rua General Glicério, 355/702 - Laranjeiras

22245-120 Rio de Janeiro, RJ, Brasil

Fone: (21) 2265-4370 (21) 9924-8885

e-mail: facramos@terra.com.br 